\title{
CONSTRUÇÕES VERBAIS COM PRONOME CLÍTICO NA ESCRITA EM PORTUGUÊS DE ESTUDANTES DE ORIGEM BOLIVIANA. ASPECTOS SINTÁTICOS E DISCURSIVOS
}

\author{
CONSTRUCCIONES VERBALES CON PRONOMBRE CLITTICO EN LA ESCRITURA EN \\ PORTUGUÉS DE ESTUDIANTES DE ORIGEN BOLIVIANO. ASPECTOS SINTÁCTICOS Y \\ DISCURSIVOS
}

\author{
Renie Robim ${ }^{1}$ \\ Adrián Pablo Fanjul ${ }^{2}$
}

\begin{abstract}
RESUMO: $O$ artigo apresenta alguns dos resultados de uma pesquisa desenvolvida sobre a produção escrita, em português, de alunos bolivianos ou filhos de bolivianos da rede municipal de ensino de São Paulo, todos eles com mais de cinco anos de escolaridade no Brasil, comparada com a de alunos brasileiros sem qualquer contato familiar com a língua espanhola. A hipótese, elaborada a partir de aproximações e observações prévias, situou as construções verbais com clítico átono sem função de objeto como aquelas que apresentariam diferenças mais substanciais. Elaborou-se uma proposta de produção textual direcionada a focalizar essas construções. Os resultados mostram, entre o grupo de bolivianos e filhos de bolivianos e o de brasileiros sem contato com o espanhol, diferenças que se concentram principalmente nas construções de valor ergativo em que os participantes nos processos denotados pelo verbo são humanos. Com base nesses resultados, e considerando um acervo de estudos comparativos entre o português brasileiro e o espanhol, o artigo apresenta interpretações e conclusões em dois planos. Por um lado, sobre a representação sintática das construções analisadas, e, por outro, sobre o funcionamento discursivo em que elas se inserem. Dessa maneira, o trabalho se propõe a contribuir para o conhecimento sobre a aquisição de português por imigrantes bolivianos e por hispanofalantes em geral, e também para os estudos que comparam o funcionamento do português e do espanhol em diferentes níveis de observação, incluindo o discursivo.

Palavras-chave: Imigração boliviana no Brasil; aquisição do português brasileiro; comparação entre português e espanhol; construções ergativas; clíticos; representação da pessoa no discurso.
\end{abstract}

RESUMEN Este artículo expone algunos de los resultados de una investigación desarrollada sobre la producción escrita, en portugués, de alumnos bolivianos o hijos de bolivianos de las escuelas municipales de São Paulo, todos con más de cinco años de escolaridad en Brasil, comparada con la de alumnos brasileños que no tienen contacto familiar con la lengua española. La hipótesis, elaborada a partir de acercamientos y observaciones previas, ubicó las construcciones verbales con clítico átono sin función de objeto como las que presentarían diferencias más sustanciales. Se elaboró una propuesta de producción textual destinada a focalizar esas construcciones. Los resultados muestran, entre el grupo de bolivianos e hijos de bolivianos y el de brasileños sin contacto con el español, diferencias que se concentran principalmente en las construcciones de valor ergativo en que los participantes de los procesos denotados por el verbo son humanos. En base a esos resultados, y considerando un acervo de

\footnotetext{
${ }^{1}$ Mestre em Letras-Língua Espanhola pela Universidade de São Paulo-USP. Professor da Licenciatura em Espanhol do Instituto Federal de Educação, Ciência e Tecnologia do Rio Grande do Sul-IFRS.

${ }^{2}$ Doutor em Linguística pela UNESP-Araraquara e Livre-Docente em Língua Espanhola pela Universidade de São Paulo-USP. Professor Associado no Departamento de Letras Modernas da Universidade de São Paulo-USP. Bolsista de Produtividade nível 2 do CNPq.
} 
estudios comparativos entre el portugués brasileño y el español, el artículo presenta interpretaciones y conclusiones en dos planos. Por un lado, sobre la representación sintáctica de las construcciones analizadas, y, por otro, sobre el funcionamiento discursivo en que se insertan. De ese modo, el trabajo se propone aportar al conocimiento sobre la adquisición del portugués por inmigrantes bolivianos y también a los estudios que comparan el funcionamiento del portugués y del español em diferentes niveles de observación, incluyendo el discursivo.

Palabras clave: Inmigración boliviana en Brasil; adquisición del portugués brasileño; comparación entre portugués y español; construcciones ergativas; clíticos; representación de la persona en el discurso.

\section{Introdução}

A imigração boliviana no Brasil, particularmente na cidade de São Paulo, é, para a pesquisa sobre a linguagem, uma possibilidade quase única de investigar fenômenos que resultam do contato entre o português brasileiro e espanhol em uma situação de migração ampla e em contexto de grande cidade. Os territórios de fronteira onde já se desenvolveram pesquisas sobre contato entre essas duas línguas (dentre muitas outras, BRAZ, 2010; ELIZAINCÍN, 2004) são, de modo geral, espaços de comunidades relativamente pequenas e não imersas em um grande conglomerado urbano.

Em especial, a presença das crianças e adolescentes bolivianos e descendentes de bolivianos na escola dá lugar a um cenário privilegiado para observação de práticas de linguagem com os mais diversos focos de interesse, da alfabetização aos processos discursivos na construção de identidades, passando por todos os níveis do funcionamento da língua.

Neste trabalho, expomos parte dos resultados de uma pesquisa desenvolvida com alunos de origem boliviana de escola pública que contam com um tempo relativamente considerável, mínimo de cinco anos, de inserção no país e na instituição escolar. A indagação foi desenvolvida sobre produções escritas direcionadas à formação de um corpus, embora tenhamos feito observações prévias sobre material produzido em aulas sem esse objetivo. As produções dos alunos de origem boliviana foram cotejadas com uma amostra de igual quantidade de casos de alunos brasileiros das mesmas escolas que não têm contato familiar com a língua espanhola. Para determinar, depois das primeiras observações, que aspectos do funcionamento linguístico focalizaríamos na pesquisa definitiva, foi importante o acompanhamento que mantemos, no núcleo de pesquisadores em que este trabalho se integrou, acerca dos estudos comparados entre o espanhol e o português brasileiro que se desenvolveram no Brasil nas últimas duas décadas, e que também indagaram aspectos da aquisição de uma dessas línguas pelos falantes da outra.

Como explicaremos ao longo do artigo, as observações do material coletado direcionaram nossa atenção principalmente para construções verbais que integram pronomes átonos em valores semânticos específicos. Decidimos, para esta publicação em especial, desenvolver também uma observação qualitativa de alguns casos a partir de uma perspectiva discursiva, com apoio de trabalhos que compararam tendências, em discursividades brasileiras e hispano-americanas, para modos de inserir, na cena enunciativa, as entidades pessoais da interlocução ou das quais se fala. Assim, este artigo tem dois objetivos. Por um lado, observar comparativamente, entre as produções escritas dos dois grupos analisados (alunos bolivianos e/ou filhos de bolivianos, e alunos brasileiros sem ascendência hispânica nem contato familiar 
com o espanhol), a ocorrência de construções verbais que integram pronomes átonos em funções diferentes das de objeto, interpretando os predomínios em cada grupo à luz de estudos prévios sobre o espanhol e o português brasileiro. Por outro lado, ampliar a observação dessas formas para a dimensão textual e discursiva em que ocorrem, e produzir uma reflexão sobre o que elas indicam como processos de inscrição dos sujeitos na ordem da língua do país de imigração.

A primeira seção do artigo expõe uma breve contextualização do coletivo boliviano em São Paulo e de sua inserção nas escolas públicas da rede municipal. No item 2, vamos explicando como chegamos, mediante diversas explorações, a delimitar o foco linguístico de observação, e, nesse percurso, apresentamos a conceitualização descritiva que consideramos para as duas línguas e para a sua comparação. A terceira parte está dedicada a expor a metodologia e os procedimentos que seguimos para a reunião do corpus. Depois, na seção 4, apresentamos as ocorrências encontradas em cada grupo para as construções verbo-pronominais que indagamos, e, além de apresentar a quantificação, desenvolvemos uma interpretação qualitativa atenta à semântica dessas construções e aos complementos que as acompanham. $\mathrm{Na}$ quinta parte, retomamos os casos correspondentes a três das bases verbais encontradas, e os analisamos a partir da configuração enunciativa, como representações de centralidade ou de distanciamento da entidade pessoal em relação ao processo que é objeto de discurso. Para tanto, ampliamos a observação a outros aspectos das produções escritas, para além das construções que foram nosso foco no resto do artigo, mas que se vinculam com a semântica das suas bases verbais. As conclusões, no item 6 , tentam avaliar o percurso realizado integrando as diversas dimensões que foram consideradas.

\section{A imigração boliviana em São Paulo e sua presença nas escolas municipais}

A imigração boliviana para o Brasil amentou consideravelmente a partir da década de 1980, chegando a ser calculada pelo Consulado boliviano em 250.000 pessoas poucos anos atrás (ROCHA, 2015). O censo de $2012^{3}$ do Instituto Nacional de Estadística del Estado Plurinacional de Bolivia mostra o Brasil como terceiro país de maior imigração boliviana, sendo o primeiro a Argentina e o segundo a Espanha. $O$ fenômeno já deu lugar a pesquisas em diversas áreas das ciências humanas, inclusive dos estudos da linguagem, como o trabalho que acabamos de referir de Rocha e o de Mandalá (2015).

A nossa pesquisa, como já antecipamos na Introdução, foi desenvolvida no âmbito do ensino básico municipal da cidade de São Paulo. Como mostram os dados a seguir, extraídos do portal "Escola On Line" da Secretaria Municipal da Educação ${ }^{4}$, os bolivianos constituíam, em 2015, a maior parte das matrículas de alunos estrangeiros:

\footnotetext{
${ }^{3}$ Disponível em http://censosbolivia.ine.gob.bo/webine/index.php , acesso em 12/9/2019.

${ }^{4}$ Portal de acesso restrito, https://eol.prefeitura.sp.gov.br/escola/se1426_asp/index.asp, acesso em 29/7/2019.
} 
Tabela 1. Alunos estrangeiros nas escolas municipais de São Paulo em 2015

\begin{tabular}{|l|l|}
\hline Estrangeiros nas escolas municipais de SP & 3.772 alunos \\
\hline Bolivianos nas escolas municipais de SP & 2.618 alunos \\
\hline Total de matrículas na rede municipal de SP & 971.028 alunos \\
\hline $\begin{array}{l}\text { Porcentagem de alunos bolivianos em relação aos } \\
\text { alunos estrangeiros }\end{array}$ & $69,4 \%$ \\
\hline $\begin{array}{l}\text { Porcentagem de alunos bolivianos em relação ao } \\
\text { total de matrículas }\end{array}$ & $0,27 \%$ \\
\hline
\end{tabular}

Segundo Niehoff (2014, p. 35), a segregação socioeconômica que caracteriza os espaços urbanos determina, nesse coletivo imigrante, dois eixos de estratificação social: por um lado, os bolivianos originários de uma classe social relativamente abastada e com formação em nível superior, por outro, em um número muito maior, os bolivianos trabalhadores das indústrias têxteis que vivem, em sua maioria, afastados do centro da cidade e dispondo de pouco tempo para as atividades culturais, sociais e lúdicas. São os filhos desses trabalhadores que estudam nas escolas públicas de São Paulo e cujos registros escritos serão analisados, neste artigo, em comparação com alunos brasileiros sem nenhum tipo de ascendência hispânica.

\section{Indagações prévias e delimitação de uma área de problemáticas no funcionamento linguístico}

Ao realizar as experiências piloto, em diversas escolas públicas do município, para detectar itens do funcionamento linguístico que se mostrassem produtivos para explorar nas produções escritas dos alunos da coletividade boliviana, tínhamos a expectativa de nos depararmos com fenômenos que têm sido amplamente estudados, nas últimas décadas, sobre diferenças sintático-semânticas entre o português brasileiro (doravante PB) e o espanhol (doravante E), bem como sobre os processos de aquisição de uma dessas duas línguas pelos falantes da outra.

Em especial, ficamos, de início, atentos a todos os aspectos relacionados à ocorrência de pronomes pessoais, já que diversos estudos consideram essa ocorrência como um parâmetro que diferencia fortemente ambas as línguas (GONZÁLEZ, 1998 e 2008; FANJUL, 2014) e que intervém de muitas maneiras nos processos de aquisição (GONZÁLEZ, 1994; YOKOTA, 2007; GAMBINI, 2012). Todos esses pesquisadores apontam tendências que também se verificam nos estudos não comparativos sobre cada uma das duas línguas: enquanto o PB favorece sujeitos pronominais plenos, a ocorrência de pronomes sujeito no E é muito restrita, porque esse pronome tem, no funcionamento do $\mathrm{E}$, um valor de contraste, com consequências argumentativas e de produção de referência ${ }^{5}$. Inversamente, o PB tem sofrido mudanças que favoreceram o objeto nulo e, de modo geral, o enfraquecimento do emprego de pronomes pessoais átonos em diversos tipos de construção, enquanto o E mostra abundância de objetos

\footnotetext{
${ }^{5}$ Neste trabalho não observaremos ocorrências de pronomes em função de sujeito, mas ilustramos esse valor de contraste com um exemplo de Fanjul (2014, p. 34). Em um enunciado como "Basta que quieras encontrar a tus empleados que ellos aparecen en el mismo instante", o pronome sujeito "ellos" seria interpretado como não correferente com "tus empleados", já que sua ocorrência aponta, primeiramente, para uma entidade diferente da que está em foco, e que deve ser procurada na informação acessível do interlocutor.
} 
pronominais, já que as condições para o objeto nulo são muito restritas, e um amplo leque de empregos de formas átonas em outras funções. González (1998, p. 247) caracteriza essa diferença nodal como "uma inversa assimetria" entre ambas as línguas para a ocorrência de pronomes pessoais sujeito e objeto, retomando uma denominação que utilizara Tarallo (1993) para comparar o PB com o português europeu, também no que diz respeito ao emprego de formas pronominais tônicas e átonas, e às mudanças históricas nesses empregos.

As produções em português de alunos bolivianos ou filhos de bolivianos, coletadas nas experiências aproximativas (ROBIM, 2018), bem como as que nos proporcionavam colegas professores de Língua Portuguesa dos ensinos Fundamental II e Médio, mostraram algo distinto da nossa expectativa inicial. Havia, sim, em relação a alunos brasileiros, diferenças perceptíveis nos usos pronominais, mas não nos aspectos mais esperados. O primeiro que percebemos foi que, quanto aos pronomes sujeito, os modos e as proporções de ocorrências eram praticamente as mesmas. A escrita, nos jovens bolivianos e filhos de bolivianos, parecia guiada pelo mesmo parâmetro que a dos jovens brasileiros, com proliferação de formas como "eu", "ele", "ela" sem valor de contraste. Talvez isso possa ser explicado porque a grande maioria das produções observadas era, como foram também as da amostra definitiva, de alunos de lares bolivianos ou mesmo nascidos na Bolívia, mas que tinham feito a maior parte da escolaridade, ou toda ela, no Brasil. Isto é, durante boa parte da infância tiveram contato constante com o português coloquial de crianças e adultos brasileiros, e, como as crianças brasileiras, deslocaram esse emprego de pronomes sujeito para escrita. Quanto aos pronomes átonos, as diferenças para preenchimento pronominal do objeto direto eram leves, e o mais relevante se concentrava na frequência de formas pronominais átonas em outras funções.

Com efeito, nessas primeiras observações prévias à amostra definitiva, empregos de átonos pseudorreflexivos ${ }^{6}$, como os de (1) e (2), ou com valor impessoal, como em (3), apareciam em uma proporção visivelmente maior nos bolivianos e filhos de bolivianos do que nos brasileiros (os casos são da amostra atual, apresentados apenas a modo de exemplo):

(1) ...ela se chama Jéssica...

(2) ....um filme que se tratava de criança pequena...

(3) ....o box onde se toma banho....

Muito especialmente nos chamava a atenção aquilo que, no atual português brasileiro, encontra-se em variação, como as construções às que correspondem os casos (1), (2) e (3) nos exemplos acima, nos quais poderia faltar o clítico sem que mudasse o valor semântico:

(1') ...ela chama Jéssica...

(2') ....um filme que tratava de criança pequena...

(3') ...o box onde toma banho... (que, segundo o contexto, no funcionamento atual do PB, pode manter valor impessoal).

\footnotetext{
${ }^{6}$ Alguns autores que consideraremos nesta seção, como Mendikoetxea (1999), denominam esses empregos de clíticos como "pseudorreflexivos" porque embora concordem com o sujeito, não compõem um valor propriamente reflexivo: em (1), Jéssica não se chama a si mesma, nem, em (2), "um filme” se trata a si mesmo.
} 
Dentre esses empregos pronominais átonos em função diferente da de objeto se destacavam os que correspondiam a construções que os estudos gramaticais e de semântica denominam como "inacusativas" ou "ergativas", termos que aqui empregaremos indistintamente. Mendikoetxea (1999, p. 1579) considera "inacusativos" os verbos intransitivos que denotam estados ou eventos não agentivos, isto é, que não dependem da vontade de um agente, tais como "existir", "crescer" ou "murchar". Castilho (2010, p. 331), analogamente, define como propriedade das construções inacusativas ou ergativas que o sujeito verbal não tem controle sobre o estado de coisas descrito pelo verbo. Perini (2008, p. 306-307) mostra que um mesmo verbo pode ocorrer na construção transitiva ou na ergativa, e dá os seguintes exemplos (numeração nossa):

(4) $O$ frentista encheu o tanque.

(5) $\mathrm{O}$ tanque encheu.

Em (4), o verbo "encher" acontece em uma construção transitiva, em que o ser denotado pelo sujeito sintático ("o frentista") pode ser visto como agente porque tem controle sobre o evento, mas em (5), construção ergativa, não há agente com controle e o único argumento do verbo, "o tanque", é, para a classificação do autor, paciente do processo.

Mendikoetxea (1999, p. 1589) denomina essa dupla possibilidade para um verbo como "alternância causativa" e observa que, em espanhol, o que distingue a variante inacusativa da transitiva do mesmo verbo é o clítico átono pseudorreflexivo. Assim, um verbo espanhol como "romper" participa de construções transitivas, e "romperse" de construções inacusativas. Se tentássemos uma tradução para o espanhol dos exemplos acima que extraímos de Perini, teríamos:

(4’) El vendedor llenó el tanque.

(5’) El tanque se llenó.

Não seria possível, em espanhol, a interpretação ergativa de (5') sem o clítico "se". Em um dos trabalhos comparativos entre PB e E que já mencionamos, González (2008, p. 5) mostra que essa necessidade do clítico para que um verbo transitivo seja interpretado como inacusativo se mantém plenamente na língua espanhola, enquanto no PB tende a perder-se como parte do mesmo processo de declínio dos átonos a que já nos referimos, e que mostramos com as possibilidades (1'), (2') e (3').

Decidimos, então, que na amostra definitiva, indagaríamos, com base em uma produção escrita, a ocorrência de clíticos átonos em funções diferentes das de objeto direto ou indireto (incluindo objetos reflexivos ou recíprocos), com especial atenção para as construções ergativas. Com essa finalidade, elaboramos o teste que explicamos no item seguinte. 


\section{Metodologia}

\subsection{Participantes}

O corpus de produções escritas foi reunido com alunos de três escolas públicas da rede municipal de ensino de São Paulo: EMEFM "Professor Derville Allegretti", EMEF "Infante Dom Henrique" e EMEF "João Domingues", todas elas da zona norte de São Paulo. Procuramos uma amostra balanceada entre os alunos bolivianos ou descendentes em primeira geração e os brasileiros sem qualquer ascendência hispânica.

Para a amostra final e o corpus definitivo, montamos uma amostra por agrupamento. Com o objetivo de chegar a 100 informantes, 50 alunos bolivianos e descendentes de primeira geração com pelo menos cinco anos de escolaridade no Brasil e 50 alunos brasileiros sem nenhuma ascendência hispânica, convidamos um número maior, já que eles precisavam ser autorizados pelos pais mediante um termo de consentimento, e poderíamos também prever casos que não fossem aproveitáveis devido à ausência de respostas no momento do teste. A obtenção de informantes do primeiro grupo ditou o ritmo do trabalho, já que, no início, ficamos com mais produções de brasileiros sem ascendência hispânica, e, para deixar as amostras com a mesma quantidade descartamos, por sorteio, casos de brasileiros.

Todos os informantes tinham entre 11 e 18 anos, estudantes da rede pública municipal e estavam matriculados no ensino fundamental II (EF II) ou médio (EM). Tentou-se o maior equilíbrio possível no que diz respeito à distribuição entres dois níveis de ensino e a faixas etárias. Os quadros a seguir detalham a composição interna das amostras.

Tabela 2 - Distribuição por nível de escolaridade

\begin{tabular}{|l|l|l|}
\hline & $\begin{array}{l}\text { Bolivianos er em } \\
\text { descendentes de 1a } \\
\text { geração }\end{array}$ & $\begin{array}{l}\text { Brasileiros } \\
\text { ascendência } \\
\text { hispânica }\end{array}$ \\
\hline Ensino Fundamental II & 34 & 28 \\
\hline Ensino Médio & 16 & 22 \\
\hline TOTAL & 50 & 50 \\
\hline
\end{tabular}

Tabela 3 - Distribuição por faixas etárias

\begin{tabular}{|l|l|l|}
\hline & $\begin{array}{l}\text { Bolivianos e e } \\
\text { descendentes de } \text { 1a }^{\mathrm{a}}\end{array}$ & $\begin{array}{l}\text { Brasileiros } \\
\text { ascendência } \\
\text { hispânica }\end{array}$ \\
\hline 11 a 12 anos & 15 & 17 \\
\hline 13 a 14 anos & 18 & 12 \\
\hline 15 a 16 anos & 13 & 13 \\
\hline 17 a 18 anos & 4 & 8 \\
\hline TOTAL & 50 & 50 \\
\hline
\end{tabular}

Indagamos também sobre as línguas faladas no lar e pelo aluno. Para uma adequada interpretação dos resultados que apresentaremos e analisaremos na seção 4, parece-nos importante começar informando dois indicadores nas respostas a essas questões, já que nos aproximam das valorizações linguísticas no grupo dos bolivianos e filhos de bolivianos. A 
resposta sobre línguas faladas no lar incluiu, em quase todos os casos, o espanhol. Apenas em 4 dos 50 casos a resposta marcada foi "somente português". Isto é, em 92\% dos casos, os informantes apontam o espanhol como pelo menos uma das línguas da casa, e em torno de $9 \%$ mencionou também alguma língua ameríndia. Nem outra questão, sobre as línguas que cada um dos informantes fala, 74\% incluiu o espanhol. Embora se trate de informações reportadas e não de observação direta do pesquisador sobre os reais hábitos de fala, parece-nos um indício significativo de que a língua espanhola goza de prestígio entre o coletivo imigrante e de que efetivamente podemos supor que, mesmo tendo nascido no Brasil ou morado neste país boa parte da vida, o contato desses adolescentes e pré-adolescentes com o espanhol se mantém, e que essa língua efetivamente faz parte de seu ambiente linguístico.

\subsection{Propostas de produção textual e coleta de dados}

Cada um dos informantes escreveu dois textos em português, portanto, como amostra definitiva, tivemos 100 textos produzidos por bolivianos e filhos de bolivianos, e 100 textos por brasileiros sem nenhuma ascendência hispânica, um total de 200 produções textuais. Uma das propostas tendia a produção de um texto descritivo sobre alguns espaços, e se direcionava a indagar a frequência dos verbos "ter" e "haver" com valor existencial, aspecto da pesquisa que não é objeto deste artigo. A outra proposta de produção escrita, que estava direcionada a observar as ocorrências de construções pronominais descritas no item anterior, era a seguinte:

Neste texto, você deverá narrar um pequeno momento da sua vida. Conte para a gente como foi a sua primeira semana de aula no ensino fundamental II ou no ensino médio na escola em que você estuda atualmente. Diga como os professores e os colegas te receberam e se aconteceu algum fato marcante. Se já conhecia a escola ou passou por dificuldades em encontrar as salas, os banheiros, o refeitório, etc. Se já tinha algum amigo ou se precisou fazer novas amizades. Por quais assuntos você mais se interessou nessa primeira semana. Tente escrever o máximo que puder, ocupando todas as linhas. Utilize caneta azul ou preta.

As propostas para a produção escrita foram precedidas por questões com dados de classificação como os que incluímos nas tabelas 2 e 3, bem como sobre línguas faladas na casa e pelo aluno, como aos que referimos no item anterior.

\section{Resultados sobre as construções focalizadas. Apresentação e análise.}

Como explicamos na seção 2, nosso foco foram as construções verbais com clítico átono em que o clítico não é objeto direto, nem reflexivo nem recíproco. Comentamos por separado as que aconteceram com a forma "se" e as que apresentaram a forma "me", e depois as comentamos conjuntamente.

\subsection{Ocorrências com o clítico "se"}

Houve 26 casos de construções verbais em que apareceu o clítico "se", com esta 
distribuição.

Tabela 4: construções verbais com "se” não reflexivo nem recíproco

\begin{tabular}{|l|l|l|l|}
\hline & $\begin{array}{l}\text { Bolivianos sem } \\
\text { descendentes de } 1^{\text {a }} \\
\text { geração }\end{array}$ & $\begin{array}{l}\text { Brasileiros } \\
\text { ascendência } \\
\text { hispânica }\end{array}$ & Total \\
\hline Ocorrências & 17 & 9 & 26 \\
\hline Bases verbais & 12 & 7 & 19 \\
\hline
\end{tabular}

Como mostra a tabela, os alunos bolivianos e filhos de bolivianos produziram $65 \%$ dos casos, e, ainda, vê-se nas suas produções uma maior diversidade de verbos com que o clítico apareceu. A observação dos casos específicos mostra diferenças ainda mais instigantes quanto à semântica das construções. Transcrevemos os contextos imediatos sem qualquer correção ortográfica, tal como a escrita se apresentou. A numeração que empregamos segue a dos exemplos apresentados neste artigo, e não a dos casos da amostra:

Bolivianos e descendentes em primeira geração:

(6) ... e nos assistimos um filme sobre Kiricul que se tratava de criança pequena ...

(7) ...Quando se passaram 3 dias ...

(8) ... e aparece um menino correndo feito um Maluco ele derrubou a professora e acabou se ferindo forte...

(9) ...tinha uma das minhas amigas que se chamava Minerva...

(10) ...mas se passaram dois anos...

(11) ...e ela se mudou de escola de casa...

(12) ...minha melhor amiga se foi...

(13) ...ela se chama Jessica....

(14) ...às vezes brigamos, mas a gente sempre se acerta no final...

(15) ...tanto tempo também que já se passou...

(16) ...pois meus pais se esforçam para dar de tudo para mim...

(17) ...e o box onde se toma banho...

(18) ...e se notava que era uma grande escola...

(19) ...ele se chamava Rafael...

(20) ...Os alunos não se importavam muito com a lição dada pelos professores...

(21) ...Praticamente não se aprendia nada por causa dos alunos pela atitude infantil...

(22) ...todos se levam bem na escola...

Brasileiros sem nenhuma ascendência hispânica:

(23) ...um menino que se chama Vinicius...

(24) ....ele se chama Adalberto...

(25) ...e quando elas não estão lá, a sala se torna minha...

(26) ...em minha casa encontram-se 7 cômodos...

(27) ...o Brasil está tentando ser algo que ele não é, se baseando no sistema de ensino do Canadá... 
(28) ...Mas depois fiquei um pouco decepcionada ao perceber que tem muitas responsabilidades e se acostumar com os novos colegas de classe....

(29) ...Minha casa se encontra no Jardim Antártica Z/N...

(30) ...Todos muito profissionais e alguns que, atualmente, já se aposentaram...

(31) ...Quando passei no ensino médio era de se esperar que muita coisa muda-se...

Em ambos os grupos, a quantidade de construções de valor estativo é a mesma: cinco casos em cada um. Interpretamos com esse valor os casos (6), (13), (9), (18), (19), (23), (24), (26), (29) e (31). Porém, a proporção é maior nos brasileiros, já que, nos bolivianos são 5 casos em 17, e nos brasileiros 5 em 9. Isto é, nos (entre) brasileiros, mais da metade dessas construções com "se" são estativas, enquanto nos (entre) bolivianos ou descendentes são menos da terceira parte.

Diferentemente, na amostra de bolivianos e filhos predominam verbos que denotam eventos dinâmicos com participantes humanos -(8), (11), (14), (16), (20), (21), (22)-, inclusive (17) apesar do valor impessoal. Entre os brasileiros sem ascendência hispânica temos apenas dois casos desse tipo de evento e participante: (28) e (30). Podemos considerar, também, que o emprego de "levar-se bem" em (22) é atribuível ao contato com o espanhol e possivelmente também (11), já que a construção pronominal para "mudar" de escola ou casa parece pouco frequente no português de São Paulo.

\subsection{Ocorrências com o clítico "me"}

Houve 52 casos em que o clítico "me" apareceu em funções diferentes da de objeto direto $(\mathrm{OD})$ ou indireto $(\mathrm{OI})$, ou de reflexivo. Para essa forma, a diferença de ocorrência entre os dois grupos foi menor que para "se":

Tabela 5: construções verbais com "me" não OD, nem OI nem reflexivo

\begin{tabular}{|l|lr|l|l|}
\hline & $\begin{array}{l}\text { Bolivianos sem } \\
\text { descendentes de } \begin{array}{r}\text { e } \\
\text { geração }\end{array}\end{array}$ & $\begin{array}{l}\text { Brasileiros } \\
\text { ascendência hispânica }\end{array}$ \\
\hline Ocorrências & 34 & 28 & 50 \\
\hline Bases verbais & 24 & 20 & 44 \\
\hline
\end{tabular}

Em compensação, foi muito perceptível a alta concentração em alguns verbos em cada grupo. Entre os alunos brasileiros sem nenhuma ascendência hispânica, foram constatados, nessa produção textual, 8 casos com a construção verbal "sentir-me" em diferentes formas finitas ou de infinitivo. Entre os alunos bolivianos e descendentes de primeira geração, entretanto, houve apenas 1 ocorrência de "sentir" com "me". Por outra parte, os alunos bolivianos e descendentes de primeira geração utilizaram 5 vezes "perder-me" em diferentes formas, sendo que esse verbo não foi utilizado pelos alunos brasileiros sem ascendência hispânica. Os alunos brasileiros que relataram ter se perdido na escola registraram isso com outro tipo de construção, como veremos ao longo deste item.

Comecemos por reconhecer que tanto "sentir-se" quanto "perder-se" são construções 
nitidamente ergativas, conforme definimos essa categoria no item 2 deste artigo. Afirmamos esse caráter ergativo porque não há controle sobre o evento por parte do participante humano que ocupa a função de sujeito sintático, e por isso o reforço reflexivo ("me perdi a/por mim mesmo", "me senti bem a/ por mim mesmo") daria lugar a uma expressão de duvidosa aceitabilidade 7 . E, dentro das ergativas, "sentir-se" e "perder-se" são construções que indicam mudança de estado. Por isso, depois de apresentar os casos, realizaremos a análise em diálogo com estudos que logo referiremos, e que abordaram comparativamente o PB e o E a respeito da expressão da mudança de estado e de posição mediante verbos, bem como da presença ou ausência de clítico nessas construções. Para iniciar a explicação, apresentamos as ocorrências, sempre com a grafia com que foram escritas pelos informantes, sem correções ortográficas.

Construções com "sentir" + "me" entre os brasileiros:

(32) ....No dia que entrei me centi muito bem...

(33) ...Quando cheguei na escola me senti perdida...

(34) ...Quando me senti estabilizada, percebi que não estava tanto assim...

(35) ....No primeiro dia de aula me senti surpresa e feliz...

(36) ...Assim que pude conhecer os professores, me senti muito bem acolhida....

(37) ...me senti muito bem...

(38) ...me senti entusiasmada com tantas matérias novas e tantos colegas...

(39) ...me fez sentir acolhida, bem recebida...

Única construção com "sentir" + "me” entre bolivianos e descendentes de 1a geração

(40) A transição de salas fazia eu me sentir como se estivesse no ensino médio.

Construções com "perder" + “me” entre bolivianos e descendentes de 1a geração

(41) ...e não tive problemas em me perder nas salas de aula...

(42) ....No primeiro dia eu não sabia que 5 ano era e acabei me perdendo...

(43) ...para decorar as salas foi bem difícil, só com o tempo mesmo, me perdi várias vezes...

(44) ...eu me perdia para encontrar as salas de aula...

(45) ...Eu não conhecia a escola e tinha às vezes a dificuldade de encontrar a sala, só não me perdia quando eu andava com o meu amigo...

O primeiro a observar é que 6 das 8 ocorrências de "sentir" + "me" em brasileiros são construções atributivas, em que a sequência verbo-pronominal é especificada por um particípio ("estabilizada", "acolhida", etc.). Inclusive "perder-se" ganhou a forma participial, no caso (33): "me senti perdida”. Todos os casos reproduzidos acima em que o particípio é também o de um verbo ergativo poderiam expressar-se mediante uma construção com núcleo verbal. Teríamos, assim "me perdi" a partir de (33), "me estabilizei” (34), "me surpreendi” (35), ou "me

\footnotetext{
${ }^{7}$ Mendikoetxea (1999, p. 1593) propõe o teste do reforço reflexivo como modo de atribuir caráter inacusativo ou ergativo a uma construção verbal. Normalmente, essas construções não o admitem.
} 
entusiasmei” (38).

Alguns estudos comparativos já realizados sobre o $\mathrm{PB}$ e o $\mathrm{E}$ podem ajudar a explicar por que a preferência nos brasileiros foi por construções atributivas com particípio, enquanto a dos bolivianos por construções de núcleo verbal.

Correa (2010, p. 176) encontra, em uma análise do corpus Amostra Censo da UFRJ que procurava determinar as representações linguísticas das construções de mudança de estado psíquico com sujeitos afetados, uma ocorrência de mais de $70 \%$ para construções atributivas no PB, como "Maria ficou irritada" e de menos de 30\% para construções de núcleo verbal, como "Maria se irritou". Em comparação, as análises do mesmo autor sobre buscas no Corpus de Referencia del Español Actual (CREA), mostram que o E "apresenta uma preferência pelo emprego de construções de núcleo verbal para a representação de eventos de mudança de estado" (CORREA 2009, p. 122). Uma assimetria semelhante quanto à preferência por construções de particípio ou adjetivo no $\mathrm{PB}$ e de núcleo verbal com clítico no $\mathrm{E}$ se verifica nos trabalhos comparativos de Araújo Júnior (2014, pp. 145-148) sobre formas passivas. Referindo levantamentos quantitativos em diferentes corpora, bem como bibliografia descritiva sobre cada uma das línguas, o autor expõe que no PB há maior incidência da passiva "perifrástica" ou “analítica” com particípio, como em "O refém foi libertado após o pagamento do resgate", enquanto no E predomina a passiva dita "pronominal", como em "este ano compraram-se mais geladeiras, fogões e máquinas de lavar que no ano passado" ${ }^{8}$. A observação tem relevância para esta discussão porque, embora as construções de mudança de estado como as que são nosso foco nesta seção não sejam, de modo geral, consideradas passivas ${ }^{9}$, elas têm em comum com as passivas o papel não agentivo do participante. Com efeito, a literatura sobre a língua espanhola que referimos neste artigo, tanto na reflexão gramatical quanto na pesquisa quantitativa, coincide em que, mesmo com participantes humanos, é menos provável uma construção participial como "Muchos participantes fueron aprobados" do que as construções verbopronominais "Se aprobaron muchos participantes" ou "Se aprobó a muchos participantes", esta última com intepretação impessoal. .

Voltando para nossos resultados, cremos que é plausível a permanência da tendência sintática própria do $\mathrm{E}$ a construções com núcleo verbal e clítico, mesmo em sujeitos que, como nossos informantes, mostram um desempenho muito consolidado na sintaxe do $\mathrm{PB}$, ao ponto de se diferenciarem pouquíssimo dos brasileiros sem contato familiar com o espanhol. Ela é possível porque, em última instância, leva para formas que, na maioria dos casos, são viáveis no $\mathrm{PB}$, embora sejam menos frequentes. Essa permanência pode explicar tanto as diferenças que vimos em relação a "se", como o que acabamos de mostrar sobre as ocorrências de "perder" e "sentir" com clítico "me", suas formas e predomínios em cada grupo.

\footnotetext{
${ }^{8}$ Exemplos de Araújo Júnior (2014, p. 134).

9 Apontamos "de modo geral" porque algumas teorizações as aproximam. Fernández Ramírez (1987, p.78) considera construções como "Los participantes se sintieron conmovidos", precisamente com o verbo "sentir", como uma variante da passiva em que "sentir" atua como auxiliar em vez de "ser". Por sua parte, Mendikoetxea (1999, p. 1586) considera que, de um ponto de vista "discursivo-funcional", as passivas e as ergativas têm em comum que fazem do objeto nocional (sujeito sintático) o tema e o tópico informativo.
} 


\section{Uma avaliação discursiva. Marcas de pessoa, sujeitos entre línguas}

Nesta seção, retomaremos e ampliaremos alguns dos dados já apresentados, para discutilos no plano do funcionamento discursivo. Situamos nossa reflexão na análise materialista do discurso, que considera a língua como materialidade da interlocução verbal, ou seja, dos enunciados ditos ou escritos (PÊCHEUX [1975] 2009, p. 77-84; HENRY [1977] 1992, p. 281). Por isso, para essa vertente teórico-metodológica, a sistematicidade da língua no seu funcionamento tem uma autonomia relativa. A língua e o discurso podem ser abordados a partir de categorias descritivas próprias e com objetivos específicos, mas também podem ser, e é desejável, objeto de uma reflexão que tente relacioná-las para interpretar a produção de sentido.

Abordaremos essa relação apoiando-nos nas contribuições que alguns pesquisadores dessa corrente produziram, no Brasil, sobre enunciações de falantes "entre línguas", por migração e/ou por aprendizagem. A partir de Celada e Payer (2016, p. 21-22), consideramos a tomada da palavra em um espaço marcado pela heterogeneidade linguística como a disponibilidade de um sujeito para realizar "certos investimentos subjetivos com poder de desencadear a série de deslocamentos que a ordem de uma língua (seu funcionamento) solicita". Esse processo dá lugar a movimentos de identificação que "acontecem numa cena invisível, simultânea e também necessária: a que ocorre nos bastidores do teatro da consciência, na relação língua(gem)/ sujeito" (idem, p. 23). Cabe apontar que a noção de "identificação" que as autoras consideram se relaciona a uma concepção não subjetivista, própria da corrente materialista do discurso que já caracterizamos no início deste item, que dá prioridade à determinação socio-histórica por cima das intenções dos falantes. Nessa linha, a identificação não supõe formulações por parte do falante do tipo "sou X" ou "penso como X", mas a inscrição não reflexiva nem intencional, no seu dizer, de traços pré-construídos na ordem discursiva que determina esse dizer (PÊCHEUX, [1975] 2009, p. 150).

Assim, cremos que as produções escritas recolhidas possibilitam observar movimentos de identificação, na materialidade do $\mathrm{PB}$, de sujeitos que têm o espanhol como língua primeira ou como uma das línguas de seu lar, em duas especificidades das suas condições de produção: serem parte da imigração boliviana em São Paulo, e o contexto de escola pública em que os textos foram produzidos. Para tanto, desenvolveremos uma avaliação qualitativa das ocorrências, expandindo sua observação para as sequências textuais que as incluem e para relações semânticas com outros tipos de recorrências na amostra.

\subsection{Perder-se, sentir-se, ser confuso. Diferentes representações da pessoa no discurso}

Já mostramos, no item anterior, que a ocorrência de formas do verbo "perder-se" pronominalizado com "me" ocorreram exclusivamente nas produções de bolivianos e filhos de bolivianos, e que a alta frequência de "sentir-se", também com "me", nos respondentes brasileiros sem ascendência hispânica se relacionava à expressão, mediante construções atributivas, como "me senti perdida" ou "me senti surpresa", do que podia ter ocorrido com uma construção verbal como "me perdi". E vimos, também, que estudos comparativos como o de Correa (2009) já apontavam uma maior frequência de construções atributivas para a 
expressão de mudança de estado no $\mathrm{PB}$ e, no $\mathrm{E}$, de construções com núcleo verbal. No mesmo trabalho, Correa tentava, a partir dos seus dados, uma generalização que diz respeito a como cada uma das duas línguas tende a conceber semanticamente os processos que envolvem participantes humanos não agentivos, como são todas as construções que ele analisava e, também, as que são objeto desta seção.

Correa considera que o espanhol tende a representar esses acontecimentos de participantes humanos não agentivos como eventos, daí a preferência por construções verbais médias, enquanto o português brasileiro os representa como estados. A partir disso, o autor estabelecia relações com estudos comparativos de cunho discursivo que indicavam tendências que poderiam encontrar uma explicação análoga: o de Serrani (2001), que observava um emprego de nominalizações muito maior nos brasileiros do que nos hispano-falantes, e o de Funjal (2002, pp. 88-98), que, comparando práticas de reformulação feitas por brasileiros e argentinos, localizava uma diferença aspectual que mostra, nos brasileiros, uma tendência a construções resultativas e estativas também para participantes não agentivos.

Porém, para situar aqui o que cada um desses estudos focaliza, convém apontar que essas pesquisas sobre o discurso, também experimentais, não tinham como objetivo ponderar aspectos da organização sintática no funcionamento da língua, mas, como todo trabalho em análise do discurso, procuravam, na linguagem verbal, determinações sócio-históricas pesando sobre os coletivos linguístico-nacionais comparados. No caso, indagavam, de diferentes maneiras e comparativamente, como são representadas, no discurso, as entidades pessoais, tanto os interlocutores como as pessoas de quem se fala, em figurações que envolvem algum tipo de conflito ou assimetria social.

Assim, Serrani (2001, p. 48), comparando enunciações de advertência e de pedido, encontra diferentes modos de representação de distância entre os protagonistas e o objeto de discurso. Autor 2 (2017), em um percurso por investigações próprias e de pesquisadores que orientou, algumas experimentais e outras comparando séries discursivas em gêneros diversos, aponta, como tendência, a delimitação mais tênue dos contornos das entidades pessoais em discursividades brasileiras quando comparadas com hispano-falantes. Recurso à genericidade, ou à denominação da entidade pessoal mediada por um conjunto mais abrangente ("uma pessoa de X características, como ele é"), ou trazida por uma perspectiva exocêntrica, isto é, a partir da percepção de outros e não da individualização por si, são alguns dos traços levantados. Enfim, processos semânticos análogos aos que a pragmática tem estudado como "atenuação" (BRIZ; ABELDA, 2013), aqui não recaindo sobre a força ilocucional, mas sobre as instâncias de pessoa e sua individualização na heterogeneidade enunciativa.

Cremos que a forma "perder-se", que só apareceu nas enunciações de bolivianos e filhos de bolivianos, mantém a centralidade da pessoa, no caso o "eu" locutor, na representação do processo. Retomando os casos apresentados na seção anterior:

(41) ...e não tive problemas em me perder nas salas de aula...

(42) ....No primeiro dia eu não sabia que 5 ano era e acabei me perdendo...

(43) ...para decorar as salas foi bem difícil, só com o tempo mesmo, me perdi várias vezes...

(44) ...eu me perdia para encontrar as salas de aula... 
(45) ...Eu não conhecia a escola e tinha às vezes a dificuldade de encontrar a sala, só não me perdia quando eu andava com o meu amigo...

Diferentemente, construções atributivas como "me senti perdida", que só apareceram na amostra de brasileiros sem ascendência hispânica, do ponto de vista enunciativo tiram o foco da centralidade da pessoa pelo seu desdobramento entre o "sentir" e a representação resultativa, entre quem percebe e quem é percebido:

(33) ...Quando cheguei na escola me senti perdida, todas as escolas que estudei eram muito menores...

A mesma respondente, em cujo texto são narradas várias situações de dificuldade de ambientação na escola, emprega depois outra construção atributiva com "sentir-se + particípio" que mostra mais claramente esse desdobramento: "quando me senti estabilizada, percebi que não estava tanto assim”.

E observando, no corpus, outros modos de como os alunos brasileiros sem ascendência hispânica deram conta da situação de desorientação no espaço da escola, vemos novas formas de descentralização da perspectiva pessoal ou de distanciamento entre pessoa e processo. Assim, temos no caso (46), a seguir, uma construção atributiva com "ficar", na qual, como em (33) o aspecto resultativo descentra a perspectiva pessoal, e, em (47) e (48), um distanciamento ainda maior dado por predicações compostas por "ser" e o adjetivo "confuso" com efeito de impessoalidade:

(46) ...Como não teria mais aulas numa sala ambiente, fiquei confusa muitas vezes sem saber para qual sala ir...

(47) ...Quando acabava a aula eu não sabia em que sala entrar, era confuso, porém, logo fiz amizades...

(48) ...só foi meio confuso nas trocas de aulas, pois era salas fixas para cada matéria / professor, então era bem confuso achar as salas...

Neste subitem abordamos a forma e os efeitos de sentido de construções que, de nosso ponto de vista, operam uma atenuação dos contornos das entidades pessoais na cena que a enunciação produz e diferentes graus de distanciamento em relação aos processos dos quais participam. No seguinte, trataremos de casos em que, diferentemente, esses contornos se reforçam e não há marcas, nem aspectuais nem de genericidade, que indiquem distanciamento.

\subsection{Surpreender-se, surpreender os outros}

Em espanhol, não apenas existe um verbo cognato de "surpreender", o verbo "sorprender", como ele também é transitivo, podendo passar a um funcionamento ergativo com o reforço pronominal, "sorprenderse". Isto é, trata-se de um verbo que participa do que em 2 apresentamos como "alternância causativa". Uma construção resultativa como "quedar sorprendido" é possível, mas a procura em corpus de referência (empregamos o Corpus del 
Español de Bringham Young University ${ }^{10}$ ) confirma que tem menos frequência que a construção ergativa verbo-pronominal "sorprenderse", ratificando estudos como o que já mencionamos de Correa (2009). Com efeito, a busca pela sequência "[quedar] (em todas as formas do verbo) + sorprendid* (com quaisquer gênero e número)" dá, nos séculos XX e XXI, 29 ocorrências; enquanto a busca por "se + [sorprender] (em todas as formas do verbo)", a pesar de incluir somente a $3^{\text {a }}$ pessoa pronominal mostra, para o mesmo período, 123 casos.

$\mathrm{Na}$ seção anterior comentamos o caso (35), que reproduzimos a seguir, que podia ter sido formulado como "me surpreendi". Foi exatamente o que aconteceu em uma das produções de bolivianos (49):

(35) ....No primeiro dia de aula me senti surpresa e feliz...

(49) ....Eu me surpreendi com a escola...

Aqui abordaremos o caso (49) na sequência textual em que se produziu, porque nos parece interessante notar como a emergência de "surpreender" aparece duas vezes relacionada à quebra de uma expectativa angustiante precisamente nas formações imaginárias (PÊCHEUX, [1969] 1997, p. 79-87), que prefiguram uma assimetria de forças entre os lugares institucionais de aluno e da escola como tal ${ }^{11}$. Este é o trecho extenso que inclui a formulação já mostrada, e que, como nas seções anteriores, transcrevemos com a idêntica escrita com que foi produzido, sem correções:

Quando entrei na escola pensei que ia ser como do meu amigo que era do $3^{\circ}$ ano, ele entrou na escola no terceiro semestre no ultimo ano de escola dele alguns professores não aceitam ele entrando no $3^{\circ}$ bimestre porque alguns professores pensavam que ele ia repetir de ano. Mais não ele surprendeu os professores eu pensei que ia ser assim comigo porque eu entrei no $2^{\circ}$ bimestre mais não na sala ja me mostraram os horarios os professores e tipo de trabalho para entregar. Nas outras escolas não foi assim eu me surprendi com a escola fiz amigo muito rapido e tambem uma escola muito otima.

O respondente nasceu na Bolívia e fez sua escolaridade inicial lá, mas a maior parte foi feita no Brasil. Junto de traços inequívocos da oralidade do português brasileiro, como "não aceitam ele”, ou, de modo geral, a abundante ocorrência de pronomes em função de sujeito sintático, sua escrita, em outros trechos mostra, em alguns poucos lugares, formas que remetem claramente ao espanhol, como "entrando na casa verás um corredor", que aparece na produção que realizou para o outro teste aplicado na pesquisa, e que não é abordado neste artigo.

O verbo "surpreender", que, no trecho que transcrevemos acima, aparece como transitivo ao relatar que o amigo dele passou de ano contra as expectativas institucionais,

\footnotetext{
${ }^{10}$ Esse corpus, criado e dirigido pelo linguista Mark Davies, é um dos mais consultados para essa língua e o que permite buscas por categorias gramaticais mais decantadas. Contém tanto escrita quanto transcrição de fala e, na modalidade que aqui consultamos, o volume textual é de 100 milhões de palavras. Encontra-se na página https://www.corpusdelespanol.org/xs.asp

${ }^{11}$ Pêcheux e, de modo geral, a análise materialista de discurso, entendem as formações imaginárias como as imagens que os interlocutores fazem uns dos outros e dos objetos dos quais falam, imagens determinadas pelos lugares que esses interlocutores ocupam na formação social.
} 
reaparece como ergativo, em uma construção pronominal em que o próprio locutor é o afetado e a escola o fator causante da surpresa. Assim, temos duas passagens para uma representação eufórica em que a entidade pessoal (primeiro o amigo, depois ele próprio) "vence" em uma projeção imaginária que, de início, lhe era desfavorável. Nas duas ocasiões, essa entidade é o centro de perspectiva, primeiro como causante do inesperado, depois como experienciador, e em ambos os casos sem qualquer traço de distanciamento a respeito do processo.

Nesta seção, as construções verbo-pronominais e atributivas de mudança de estado que tinham aparecido com mais recorrência nas amostras foram indagadas na sua sequência textual e como regularidades discursivas. Cremos que parecem emergir, no dizer destes imigrantes ou filhos de imigrantes como lugares de identificação que se abrem para o funcionamento de outra das línguas que constituem sua subjetividade e sua história familiar e pessoal, o espanhol. E emergem precisamente em pontos, como mostraram os casos de "perder-se" e "surpreender-se", em que se representa, disfórica ou euforicamente, a inserção desses sujeitos em um espaço, o da escola, que talvez seja o que mais nitidamente os solicita na língua não imigrante.

\section{Considerações finais}

Os resultados da pesquisa indicam que a escrita dos estudantes bolivianos ou descendentes de primeira geração apresenta diferenças sutis em comparação com a dos brasileiros sem nenhuma ascendência hispânica. Os alunos da comunidade boliviana conseguem enunciar em PB mostrando poucas dessemelhanças, na materialidade da escrita, quando comparada com os brasileiros da mesma idade que não têm contato familiar com a língua espanhola.

O fato de que as diferenças mais visíveis se mantenham em torno de construções verbais com clítico átono, que incluso dentro do PB se encontram em variação, contribui para esse efeito de sutileza. São formas possíveis no atual funcionamento da língua, apesar de estarem em retrocesso no quadro de mudanças que o $\mathrm{PB}$ vem experimentando conforme todos os pesquisadores que aqui referimos ${ }^{12}$. E o fato de que a diferença entre ambos os grupos para essas construções se dê principalmente em formulações com participantes humanos, e mais concentradamente em aquelas que indicam mudança de estado tende, também, a confirmar que o parâmetro proposto por Correa (2009) como diferenciador dos atuais PB e E tem força suficiente para incidir na fala de indivíduos bilingues plenamente inseridos no funcionamento do PB. Por outra parte, quando observadas no plano da configuração enunciativa e na dimensão textual, como fizemos na última seção do artigo, podemos ver que a especificação lexical dessas construções permite observar relações com as formações imaginárias próprias da prática discursiva e do âmbito institucional em que se inserem. Para tanto, mostrou-se produtivo o recurso a estudos que já compararam tendências para a configuração enunciativa em discursividades brasileiras e hispano-americanas.

\footnotetext{
${ }^{12}$ Recapitulando, Tarallo (1993), Castilho (2010), Perini (2008). Este último, precisamente, aponta que os verbos que podem funcionar em construções tanto transitivas como ergativas se encontram em processo de expansão no $\mathrm{PB}$, e que o pronome átono (que ele caracteriza como "reflexivo") tende a não empregar-se no "coloquial" (idem, p 308-310).
} 
Cremos que o resumido nos dois parágrafos anteriores constitui o principal aporte deste artigo e da pesquisa em que ele se sustenta, e que também aponta os limites em que essa contribuição deve ser interpretada. Conseguimos mostrar, na análise de produções escritas, um forte indício do que subsiste na aquisição do PB por falantes de E, especificamente de origem boliviana, que já contam com um longo contato e escolarização na língua alvo, contato que, para alguns deles, começou quase simultaneamente que com o E, a língua mais falada no coletivo migrante do que provêm. Uma pesquisa que se centrasse em jovens do mesmo coletivo com menos tempo de contato, ou em modalidades orais poderia mostrar não apenas outras construções de interesse para o observador, como também iluminar aspectos do processo de aquisição que digam mais sobre os próprios resultados que apresentamos aqui. Se este trabalho conseguir despertar esse interesse e apontar uma zona promissória para indagar, terá realizado mais uma contribuição.

\section{Referências}

ARAÚJO JÚNIOR, B. As formas passivas. In: FANJUL, A. e GONZÁLEZ, N. (orgs.) Espanhol e portugués brasileiro: estudos comparados. Parábola: São Paulo, 2014.

BRAZ, E. Linguas e identidades em contexto de fronteira Brasil / Venezuela. Dissertação (Mestrado em Linguística Aplicada). Universidade Estadual de Campinas, Campinas, 2010.

BRIZ, A.; ABELDA, M. Una propuesta teórica y metodológica para el análisis de la atenuación lingüística en español y portugués. La base de un proyecto en común. Onomázein, Santiago de Chile, número 28, pp. 288-319, 2013.

CASTILHO, A. Nova gramática do português brasileiro. São Paulo: Contexto, 2010.

CELADA, M. T.; PAYER, O. Sobre sujeitos, língua(s), ensino. Notas para uma agenda. In: CELADA, M. T.; PAYER, O. (orgs.) Subjetivação e processos de identificação. Sujeitos e línguas em práticas discursivas - inflexões no ensino. Campinas: Pontes, 2016.

CORREA, P. Variación aspectual y sintáctica en las construcciones de cambio de estado en español: una mirada desde el portugués. Cadernos de Letras da UFF, Niterói, número 41, pp. 167 184, 2010.

CORREA, P. Estructuras atributivas de interlengua y la organización sintáctica del portugués y del español. Signo $\mathcal{E}$ Seña, Buenos Aires, número 20, pp. 115-32, 2009.

ELIZAINCÍN, A. Las fronteras del español con el portugués en América. Revista Internacional de Lingüistica Iberoamericana, Madri, vol 2, número 2(4), pp. 105-118, 2004.

FANJUL, A. Português e espanhol: linguas próximas sob o olhar discursivo. São Carlos: Claraluz, 2002.

FANJUL, A. Conhecendo assimetrias: a ocorrência de pronomes pessoais. In: FANJUL, A.; GONZÁLEZ, N. (orgs.). Espanhol e portugués brasileiro: estudos comparados. São Paulo: Parábola, 2014.

FANJUL, A. A pessoa no discurso. Português e espanhol, novo olhar sobre a proximidade. São Paulo: Parábola, 2017. 
FERNÁNDEZ RAMÍREZ, S. Gramática española. El verbo y la oración. Madri: Arco Libros, 1987.

GAMBINI, A. La producción de los clíticos me/nos en español lengua extranjera por hablantes no nativos (HNN) brasileños en situación de exposición a la lengua por inmersión. Dissertação (Mestrado em Espanhol como Língua Estrangeira). Universidad Nacional de Córdoba, Córdoba, 2012.

GONZÁlEZ, N. Cadê o pronome? O gato comeu. Os pronomes pessoais na aquisição / aprendizagem do espanhol por brasileiros adultos. Tese (Doutorado em Linguística). Universidade de São Paulo, São Paulo, 1994.

GONZÁlEZ, N. Pero ¿Qué gramática es esta? Los sujetos pronominales y los clíticos en la interlengua de brasileños adultos aprendices de español/LE. RILCE, Pamplona, número 14-2, pp. 243-263, 1998.

GONZÁLEZ, N. Portugués brasileño y español: lenguas inversamente asimétricas. Signos Ele,

Buenos Aires, número 2, pp. 1-7, 2008. Disponível em: <https://p3.usal.edu.ar/index.php/ele/article/view/1394/1945> Acesso em: setembro 2019.

HENRY, P. A ferramenta imperfeita. Língua, sujeito e discurso [1977]. Trad. Maria Fausta P. de Castro. Campinas: Ed. Da UNICAMP, 1992.

MANDALÁ, P. Aspectos fonético-fonológicos e culturais da produção textual de alunos brasileiros e bolivianos de uma escola pública paulistana. Dissertação (Mestrado em Letras). Universidade de São Paulo, São Paulo, 2015, 115p. Disponível em: <http://www.teses.usp.br/teses/disponiveis/8/8142/tde-09062015-131019/pt-br.php> Acesso em: setembro de 2019 .

MENDIKOETXEA, A. Construcciones inacusativas y pasivas. In: BOSQUE, I.; DEMONTE, V. (eds.). Gramática descriptiva de la lengua española. Vol. 2. Madrid: Espasa, 1999.

NIEHOFF, S. Bolivians Immigrants in São Paulo. A sociolinguistic study of language contact in the city. Berlim, 2014. Dissertação (Mestrado em Sociologia). Universidade de Berlim, Berlim, 2014, 278p. Disponível em: <https://refubium.fuberlin.de/bitstream/handle/fub188/7671/Niehoff_Bolivian_immigrants_Sao_Paulo.pdf?seque nce $=1 \&$ isAllowed $=y>$ Acesso em: agosto 2019 .

PÊCHEUX, M. Análise automática do discurso [1969]. In: GADET, F.; HAK, T. Por uma análise automática do discurso: uma introdução à obra de Michel Pêcheux. Tradução de Bethânia Mariani. Campinas: Ed. da UNICAMP, 1997.

PÊCHEUX, M. Semântica e discurso. Uma crítica à afirmação do óbvio. [1975] Tradução de Eni Orlandi. Campinas: Ed. da UNICAMP, 2009.

PERINI, M. Estudos de gramática descritiva. As valências verbais. São Paulo: Parábola, 2008.

ROBIM, R. Comparação da escrita em português brasileiro de alunos bolivianos e descendentes de primeira geração com alunos brasileiros sem nenhuma ascendência hispânica. IN: PEREIRA, D.; AMATO, L.; FORTES, L.; SOUZA, L. Estudos de linguagem. Anais do IX Congresso Brasileiro de Hispanistas. Foz do Iguaçu: Associação Brasileira de Hispanistas, 2018, pp.185-210. Disponível em: http://www.hispanistas.org.br/wpcontent/uploads/2018/05/Anais-IXCBH-Ensino-de-1\%C3\%ADnguas-e-estudos-delinguagem.pdf Acesso em setembro 2019.

ROCHA, J. Da flor dos Andes a qhathu no Pari. Memórias discursivas e deslocamentos na Feira 
Kantuta. Dissertação (Mestrado) - Faculdade de Filosofia, Letras e Ciências Humanas, Universidade de São Paulo. São Paulo, 2015, 122p. Disponível em: <http://www.teses.usp.br/teses/disponiveis/8/8145/tde-06082015-103616/pt-br.php>.Acesso em: agosto 2019.

SERRANI, S. Resonancias discursivas y cortesía en prácticas de lecto-escritura. DELTA, São Paulo, número 17, pp. 31-58, 2001.

TARALLO, F. Sobre a alegada origem crioula do português brasileiro. In: ROBERTS, I.; KATO, M. (orgs.) Português brasileiro: uma viagem diacrônica. Homenagem a Fernando Tarallo. Campinas: Editora da Unicamp, 1993.

YOKOTA, R. O que eu falo não se escreve. E o que eu escrevo alguém fala? A variabilidade no uso do objeto anafórico na produção oral e escrita de aprendizes brasileiros de espanhol. Tese (Doutorado em Letras). Universidade de São Paulo, São Paulo, 2007, 219p. Disponível em: <http://www.teses.usp.br/teses/disponiveis/8/8145/tde-06112007-114658/pt-br.php> Acesso em setembro de 2019.

Recebido em: 30/09/2019

Aceito em: 03/11/19 